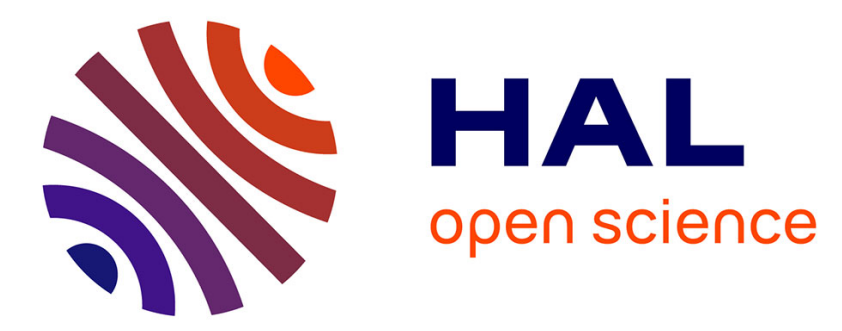

\title{
Use of a skin perforator flap pedicled by the intercostal muscle for reconstruction of a posterior cervical defect
}

\author{
B Menardais, P J Le Reste, J Duisit, E Watier, F M Leclère, N Bertheuil
}

\section{To cite this version:}

B Menardais, P J Le Reste, J Duisit, E Watier, F M Leclère, et al.. Use of a skin perforator flap pedicled by the intercostal muscle for reconstruction of a posterior cervical defect. Annales de Chirurgie Plastique Esthétique, 2021, 66 (1), pp.76-79. 10.1016/j.anplas.2020.01.004 . hal-02569414

HAL Id: hal-02569414

https://hal-univ-rennes1.archives-ouvertes.fr/hal-02569414

Submitted on 19 May 2020

HAL is a multi-disciplinary open access archive for the deposit and dissemination of scientific research documents, whether they are published or not. The documents may come from teaching and research institutions in France or abroad, or from public or private research centers.
L'archive ouverte pluridisciplinaire HAL, est destinée au dépôt et à la diffusion de documents scientifiques de niveau recherche, publiés ou non, émanant des établissements d'enseignement et de recherche français ou étrangers, des laboratoires publics ou privés. 


\section{Use of a skin perforator flap pedicled by the intercostal muscle for reconstruction of a posterior cervical defect.}

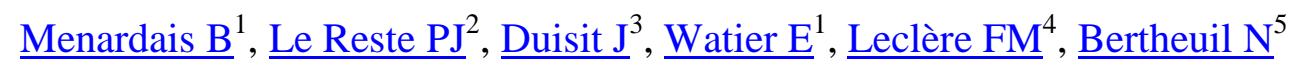

1 Department of plastic, reconstructive and aesthetic surgery, hospital Sud, university of Rennes 1, Rennes, France.

2 Department of neurosurgery, university of Rennes 1, Rennes, France.

3 Department of plastic and reconstructive surgery, cliniques universitaires Saint-Luc, université catholique de Louvain, Brussels, Belgium.

4 Department of plastic, reconstructive and aesthetic surgery, $\mathrm{CHU}$ of Poitiers, Poitiers, France.

5 Department of plastic, reconstructive and aesthetic surgery, hospital Sud, university of Rennes 1 , Rennes, France; Inserm U1236, university of Rennes 1, Rennes, France; SITI laboratory, établissement français du sang Bretagne, Rennes university hospital, Rennes, France.

Electronic address: nbertheuil@gmail.com. 


\title{
Use of a skin perforator flap pedicled by the intercostal muscle for reconstruction of a posterior cervical defect
}

\begin{abstract}
A posterior cervical defect featuring exposed spinal and occipital bone can be covered in various ways. The "ideal” flap should be a low-morbidity, pedicled locoregional flap that can reach the occiput. Cervical adjuvant radiation therapy may limit the coverage options, because many pedicles are located in areas that are often irradiated. Here, we describe a new surgical technique; we used a skin perforator flap pedicled by the intercostal muscle to cover a posterior cervical defect in a patient with metastatic squamous cell lung carcinoma. This technique is a valuable option; the flap originated from outside the irradiated area and reached the occiput. It adds to the options for cervical coverage in patients who require head-and-neck reconstruction.
\end{abstract}

\section{Résumé}

Les pertes de substances cervicales postérieures avec exposition osseuse peuvent être couverte par plusieurs techniques. Le lambeau idéal doit avoir une faible morbidité, réalisable facilement, être un lambeau pédiculé locorégional et pouvoir atteindre l’occiput. En cas de radiothérapie cervicale, certains lambeaux classiques permettant de couvrir ce type de perte de substance peuvent avoir leur pédicule endommagé. Dans cet article nous rapportons l'utilisation d'un lambeau perforant thoracique latéral pédiculé par les muscles intercostaux utilisé pour couvrir un défect cervical postérieur dans les suites d'une ostéosynthèse d'une métastase d'un carcinome pulmonaire. Ce lambeau est une alternative aux lambeaux traditionnels dont le pédicule est en dehors du champ d'irradiation. Il offre une option supplémentaire pour traiter ces défects.

Evidence Based Medicine Level V: Opinions of respected authorities, based on clinical experience, descriptive studies, or reports of expert committees.

\section{Introduction}

The use of a flap to cover a posterior cervical defect featuring exposed spinal and occipital bone is difficult. Flaps used for this purpose may be locoregional or free. An "ideal” flap should be a pedicled locoregional flap that can be harvested quickly and easily without 
muscular sequelae and with minimal morbidity; the flap should reach the occiput. Adjuvant radiation therapy may reduce the available options; free flaps are frequently used ${ }^{1,2}$. Three principal types of pedicled flap are available: the trapezius myocutaneous, latissimus dorsi, and dorsal intercostal artery propeller perforator flaps. We present a case in which none of these flaps was suitable. We created a skin perforator flap pedicled by the intercostal muscle; we previously used this flap to cover tracheoesophageal fislulae ${ }^{3,4}$ that developed after surgery to treat esophageal carcinoma. The flap afforded satisfactory esthetic and functional results. To our knowledge, this report is the first to describe the use of this flap to cover a posterior cervical defect.

\section{Case report}

A 62-year-old man with a history of asthma, osteoporosis, and disc herniation at L1S5 treated by laminectomy and osteosynthesis, and who was being weaned from a smoking addiction and alcoholism, was admitted to Rennes University Hospital for treatment of severe metastatic C2 osteolysis including the odontoid (Fig. 1). The primary tumor was an inoperable TxN3M1b squamous cell carcinoma of the lung that was first treated by six injections of carboplatin (TEVA, Petah Tikva, Israel) and Taxol (Bristol Myers Squibb, New York, NY, USA) over a period of 4 months. Opdivo (Bristol Myers Squibb) was then introduced as a second-line treatment; the patient had recently received his $32^{\text {nd }}$ injection. At the last followup, the patient's lung disease had been found to be controlled by the immunotherapy. The C2 metastasis was initially treated via two occipitocervical arthrodeses; the postoperative course was uneventful. Adjuvant external-beam radiation therapy (37.5 Gray) was then delivered. Three months postoperatively, wound dehiscence was evident on top of the scar. The patient was then lost to follow-up. He reconnected with his neurosurgeon 20 months after surgery, with a 1.5-cm-diameter occipitocervical defect featuring exposure of material. Computed tomography of the cervical region revealed complete bone remodeling and consolidation, allowing removal of the material without any further need for immobilization. Two years after the initial surgery, a re-operation was performed with the patient in the left lateral decubitus position under general anesthesia. Radiodermatitis (LENT-SOMA score $=4$ ) was apparent; we debrided the wound (Figure 1), removed the material, and took several bone samples for bacteriological testing. The cavity created by the loss of substance was $9 \mathrm{~cm}$ in height, $10 \mathrm{~cm}$ in width, and $5 \mathrm{~cm}$ in depth; bone was exposed from the occiput to C5. We harvested a skin 
perforator flap pedicled by the intercostal muscle and translated it subcutaneously; we thus used a mini-invasive technique to cover the defect.

Briefly, three perforators were preoperatively identified in the fifth intercostal space using an 8-MHz handheld Doppler ultrasonographic device. After incision, we created a $14 \times$ 7-cm elliptical skin flap to allow primary closure of the donor site. Two perforators were visualized under the fascia, dissected, and skeletonized. The flap was next harvested subfascially in the distal to proximal direction. The fifth and sixth costal planes were exposed, and the periostea of the two ribs were incised and separated from the bone along the intercostal muscle. The subcostal pedicle was ligated anteriorly to the perforator vessels. With the aid of finger dissection, the parietal pleura was incised, but not detached from the intercostal muscle (Figure 2A\&B). The flap was then dissected beyond the latissimus dorsi muscle (which was preserved). After harvesting, the flap was moved to the neck defect (Figure 3) via a submuscular and subcutaneous tunnel (beneath the trapezius muscle). Cervical and chest drains were placed, and the skin flap was sutured around the cervical cavity using interrupted, non-absorbable 3-0 sutures; the thoracotomy was then closed.

The bone samples were positive for methicillin-sensitive Staphylococcus aureus. Antibiotic treatment (intravenous tazocillin; Pfizer, New York, NY, USA) was commenced perioperatively; oral Rifadine (Sanofi Aventis, Paris, France) and Ciflox (Bayer, Leverkusen, Germany) were then added for a total of 42 days. The postoperative period was marked by venous congestion of the flap, probably attributable to constriction of the pedicle under the trapezius muscle. This complication was resolved via leech therapy. We removed the chest drain without complications on postoperative day 7 and discharged the patient to home on day 15. He remains alive 18 months postoperatively (Figure 4A \& B).

\section{Discussion}

We here describe an innovative surgical technique; we used a skin perforator flap pedicled by the intercostal muscle to cover a posterior cervical defect. Only a few pedicled locoregional flaps can be created. The use of a propeller perforator flap ${ }^{5}$ or a flap pedicled by another muscle might have been an option. This report is the first to describe the use of our flap for head-and-neck reconstruction. Of value, propeller perforator flaps are not associated with muscular sequelae. In the head-and-neck region, such a flap can be harvested if the dorsal intercostal artery perforator is present. We found no vessel close to the defect, probably because of the radiation therapy and prior surgery. Flaps fed by the transverse cervical 
arteries are often used to cover head-and-neck defects; the flaps include myocutaneous trapezius $^{6}$, muscle-sparing trapezius ${ }^{7}$, propeller $^{8}$, and island perforator flaps ${ }^{9,10}$. We did not choose any of these options because the pedicles lay in the irradiated area and we did not want to risk placement of a poorly vascularized flap. The trapezius musculocutaneous flap is reliable and robust when head-and-neck reconstruction is required, affording a large arc of rotation in the absence of any major functional deficit. However, the flap is vascularized by the suprascapular artery (a branch of the transverse cervical artery), which may have been damaged by the radiation therapy. Another possibility was a muscular latissimus dorsi flap, which is well vascularized by the thoracodorsal artery, quick to harvest, and affords robust coverage. Its preparation is simple and reliable, associated with the removal of a large area of skin. We did not favor this option as a first-line treatment because postoperative muscle sequelae were likely. The preservation of latissimus dorsi muscle function was essential because the two arthrodeses had been associated with major functional limitations. Otherwise, this flap would have been a good alternative.

We have used skin perforator flaps pedicled by the intercostal muscle eight times ${ }^{11,12}$ to treat tracheobronchial fistulae developing after esophageal carcinoma resections. The flap affords several advantages. First, the pedicle is long (up to $30 \mathrm{~cm}$ ), thus allowing access to remote (e.g., intrathoracic) defects, but also extrathoracic defects that include the occiput. The flap is easily and safely harvested with primary closure of the donor site if the skin paddle is not too wide (not $>8 \mathrm{~cm}$ ). In the present case, the pedicle had not been damaged by the radiation therapy. The flap is rather thick, permitting good bone coverage and yielding a pleasing esthetic result. A disadvantage is that the chest cavity must be opened and, therefore, a chest drain must be placed. This procedure can be painful, but was not so in our patient. We encountered flap venous congestion that resolved after leech therapy ${ }^{13}$. The congestion may be attributable to the tunneling of the flap along the costal plane under the trapezius muscle, which may have compressed the flap. It might have been better to have passed the flap over the muscle.

In conclusion, to our knowledge, this report is the first to describe the use of this flap to cover the posterior cervical area; the outcome was good. Our approach is feasible and safe, and is a useful new option for head-and-neck reconstruction.

\section{COMPLIANCE WITH ETHICAL STANDARDS}


Conflict of Interest statement : authors declare that they have no conflicts of interest to disclose.

Statement of human and animal rights, or ethical approval : This article does not contain any studies with human participants or animals performed by any of the authors.

Informed consent : For this type of study informed consent is not required.

\section{References}

1. Goh SLC. Outcome predictors in elderly head and neck free flap reconstruction: A retrospective study and systemic review of the current evidence. JPRA Surg. 2018 May;71(5):719-728

2. O’Connell JE, Mandeep S Bajwa, Andrew G. Schache, Richard J. Shaw. Head and neck reconstruction with free flaps based on the thoracodorsal system. Oral Oncology. 2017 Dec;75:46-53

3. Bertheuil N, Cusumano C, Meal, C et al. Skin perforator flap pedicled by intercostal muscle for repair of a tracheobronchoesophageal fistula. Ann Thorac Surg. 2017 103:571-573.

4. Bertheuil N, De Latour B, Meunier B. Skin perforator flap pedicled with intercostal muscle: Additional data. Ann Thoracic Surg. 2018;105:e990.

5. Kneser U, Beier JP, Dragu A, Arkudas A, Horch RE. Transverse cervical artery perforator propeller flap for reconstruction of supraclavicular defects. JPRA Surg. 2011;64:952-954.

6. Lynch JR, Hansen JE, Chaffoo R, et al. The lower trapezius musculocutaneous flap revisited: versatile coverage for complicated wounds to the posterior cervical and occipital regions based on the deep branch. Plast Reconstr Surg. 2002;109 (2):444-450. 
7. Nascimento R, Costa J, Horta R, Silva Á. Trapezius perforator flap for reconstruction of a posterior cervical defect. J Clin Orthop Trauma. 2017;8 (2):139-141.

8. Okada M, Ikeda M, Uemura T, Takada J, Nakamura H. A propeller flap based on the thoracoacromial artery for reconstruction of a skin defect in the cervical region: A case report. JPRASurg. 2013;66 (5):720-722.

9. Giordano L, Di Santo D, Occhini A, et al. Supraclavicular artery island flap (SCAIF): a rising opportunity for head and neck reconstruction. Eur Arch Otorhinolaryngol. 2016;273(12):4403-4412.

10. Chen WL, Deng YF, Peng GG, et al. Extended vertical lower trapezius island myocutaneous flap for reconstruction of cranio-maxillofacial defects. Int $J$ Oral Maxillofac Surg. 2007;36(2):165-170.

11. Grimminger PP, Goense L, Gockel I, et al. Diagnosis, assessment, and management of surgical complications following esophagectomy. Ann N Y Acad Sci. 2018 Dec;1434(1):254-273.

12. Bertheuil N, Isola N, Bergeat D, et al. Thoracotomy and esophageal surgery: Key points to preserve the possibilities of flaps. Ann Chir Plast Esthet. 2019 Apr;64(2):195-198.

13. Herlin C, Bertheuil N, Bekara F, Boissiere F, Sinna R, Chaput B. Leech therapy in flap salvage: Systematic review and practical recommendations. Ann Chir Plast Esthet. 2017;62:e1-e13. 
Figure Legends

Fig 1: The cervical defect after wound debridement. The irradiated skin was removed. The cavity created by the loss of substance was $9 \mathrm{~cm}$ in height, $10 \mathrm{~cm}$ in width, and $5 \mathrm{~cm}$ in depth; bone was exposed from the occiput to C5.

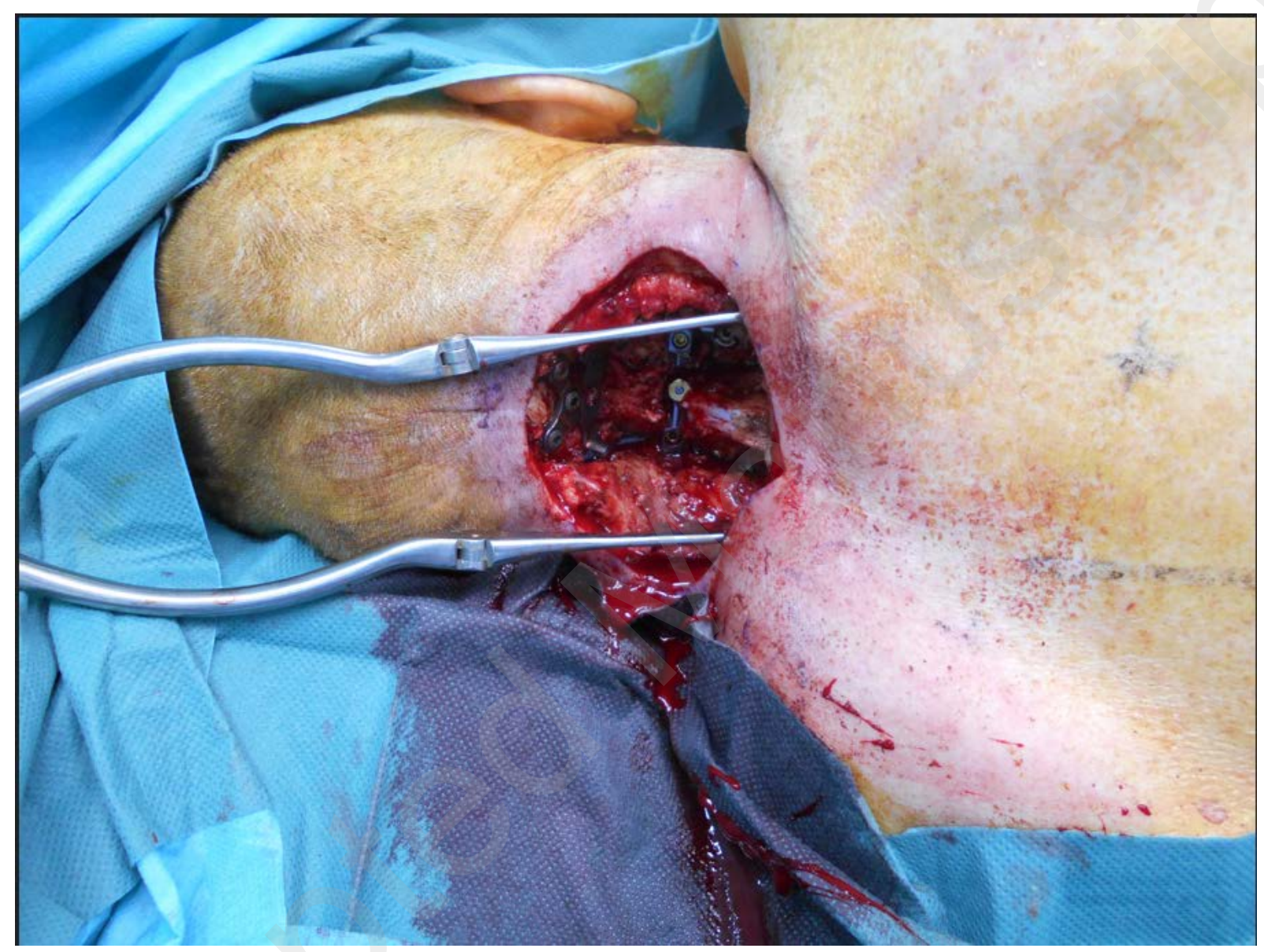

Fig 2: The skin perforator flap (LICAP) pedicled by intercostal muscle harvesting. Anterior chest view in left lateral decubitus. 

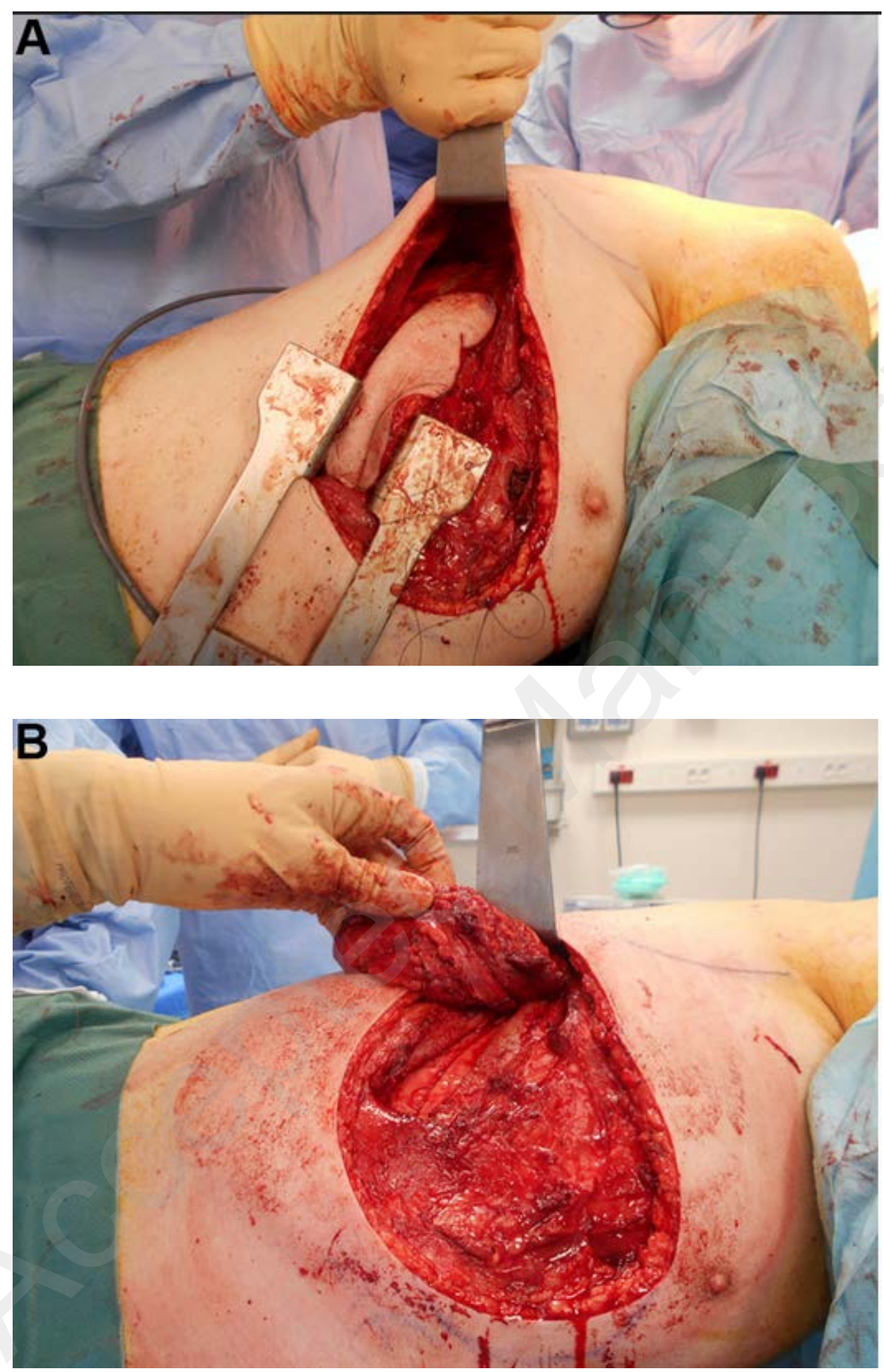

Fig 3: The flap at the end of surgery. Posterior cervical and chest view in left lateral decubitus. 


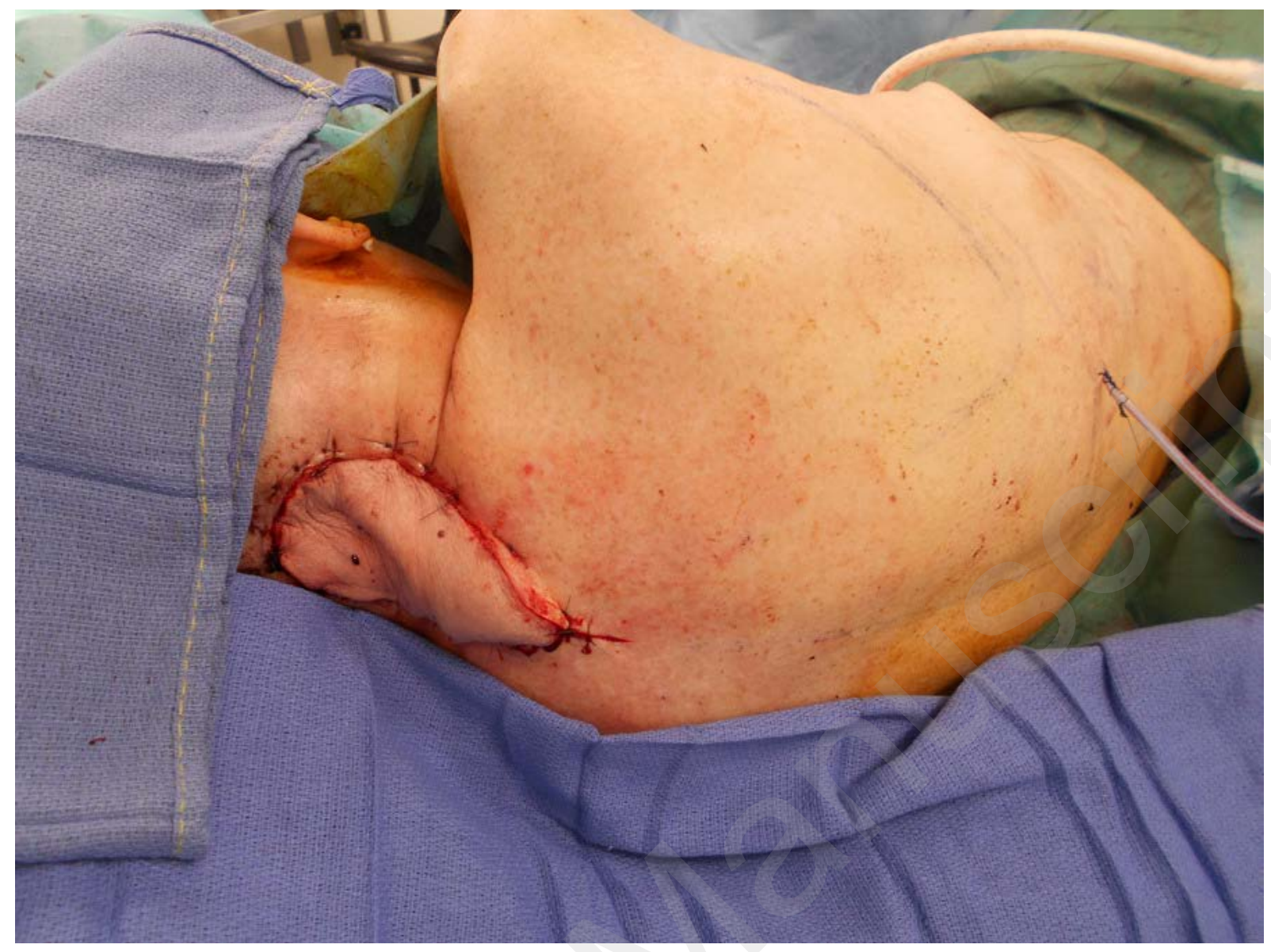

Fig 4 A\&B: Post-operative result at 18 months. 

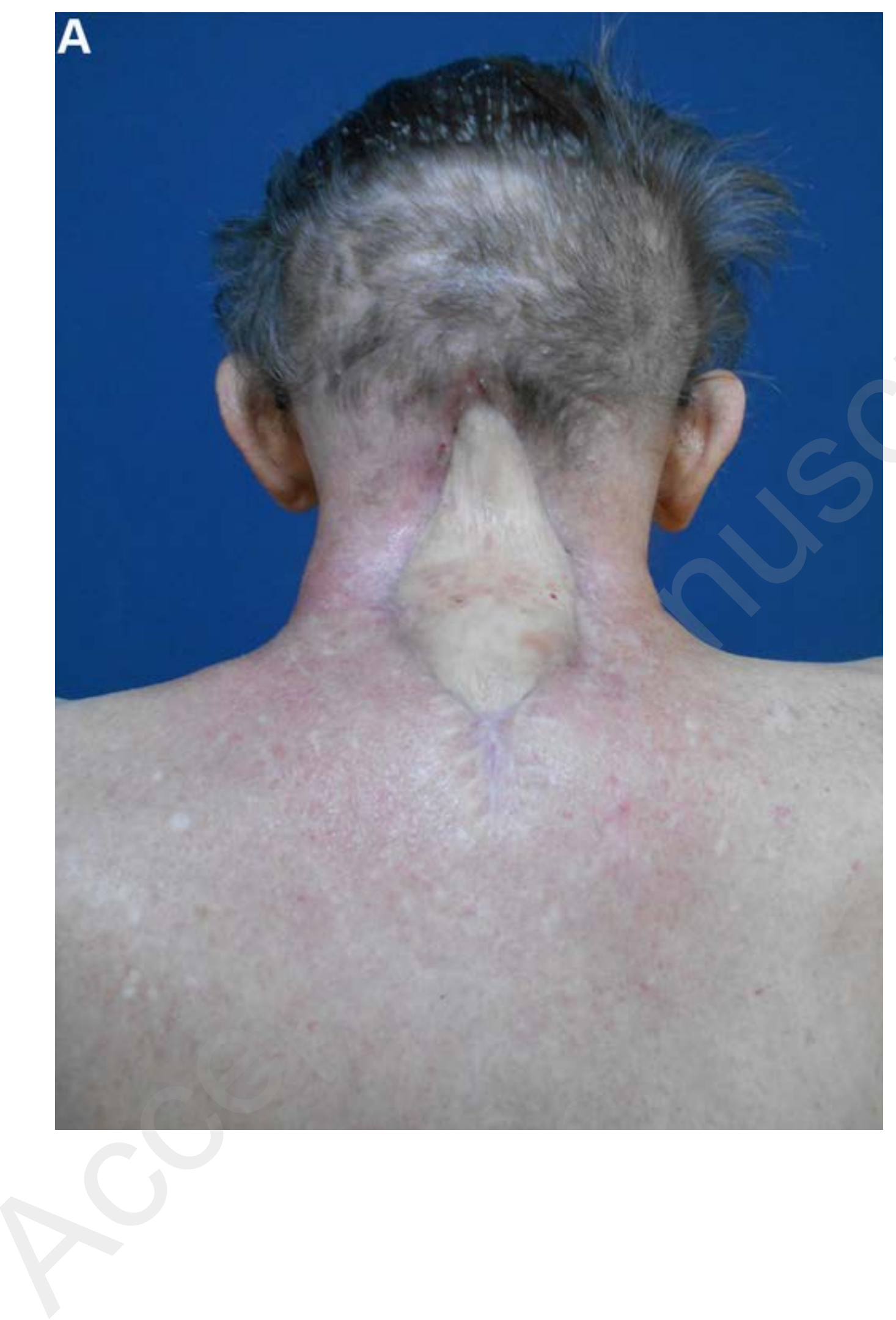


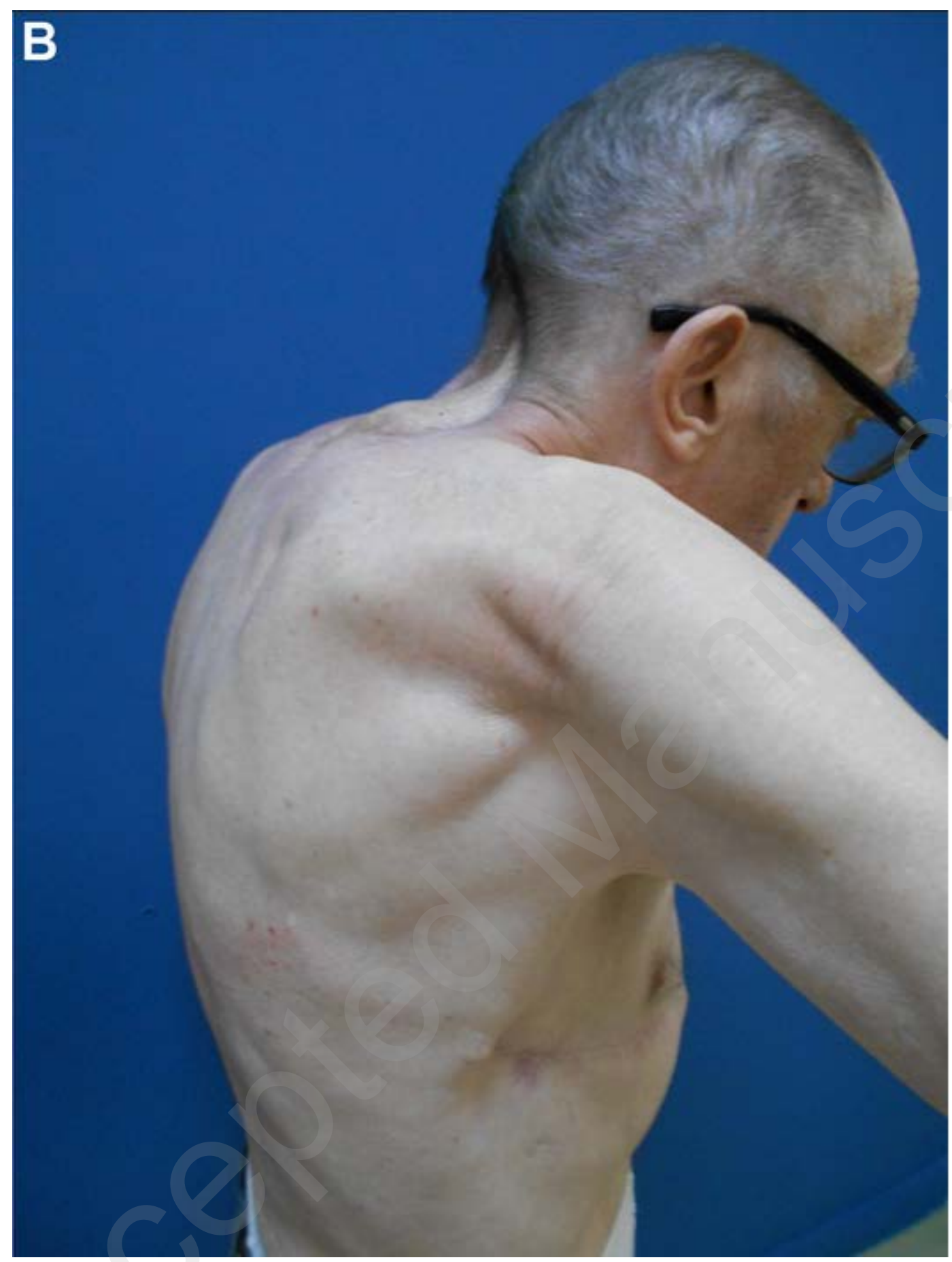

